\title{
Removal Of Methylene Blue From Aqueous Solution Using Expanded Perlite
}

\author{
Xia Zhao* a), Yabin $\mathrm{Li}^{\text {b) }}$, Xiang $\mathrm{Li}^{\mathrm{c}}{ }^{\mathrm{c}}$, Heming Luo ${ }^{\mathrm{d})}$ and Hang Zhang ${ }^{\mathrm{e}}$ \\ College of Petrochemical Technology, Lanzhou University of Technology, Lanzhou 730050, China \\ a)zhaoxia@lut.cn \\ b) successlyb@163.com \\ c)1033138056@qq.com \\ d)luohm666@163.com \\ e)809212328@qq.com
}

\begin{abstract}
The adsorbent of expanded perlite (EP) was investigated to determine the removal effect on methylene blue (MB) from wastewater through static adsorption. The factors, such as adsorbent dosage, shaking time, temperature, and $\mathrm{pH}$, were investigated. The optimum dosage, shaking time, temperature, and $\mathrm{pH}$ was $0.80 \mathrm{~g}, 100 \mathrm{~min}, 20{ }^{\circ} \mathrm{C}$, and 5.67, respectively. Isotherm analysis showed that the patterns of MB adsorption onto expanded perlite was not in line with two adsorption isotherm models, namely, Langmuir and Freundlich. The kinetic characteristics of adsorption were also evaluated. The adsorption process of the MB onto EP was in accordance with the pseudo second-order rate equation. Under ideal experimental parameters, the MB removal efficiency was $94.12 \%$ for EP, which indicated that EP is a potential adsorbent for the treatment of MB wastewater.
\end{abstract}

Keywords: Expanded perlite; Adsorption; Methylene blue; Wastewater

\section{INTRODUCTION}

China is the world's largest dye producer. Consequently, environmental pollution in China has become severe. Owing to the advent of increasingly complex dye structures and the development of the dye industry, dyes demonstrate stable performance, which makes dye wastewater treatment highly complicated. Dye as a contaminant is toxic to human beings and aquatic life; for example, if dyes enter the eyes, burns and even permanent damage could occur [1]. Dyes in aqueous environments provide undesirable color to water and reduce the penetration of sunlight. The breakdown products of dyes in water can also be toxic [2], carcinogenic, or mutagenic to life forms [3, 4]. MB, a common cationic dye, is widely used to dye cotton, leather $[5,6]$. Consequently, removing MB from aqueous solutions is a difficult requirement faced by leather and dye manufacturing. The use of different sewage treatment technologies to deal with different types of dye wastewater to meet wastewater discharge or recycling standards is an urgent problem.

Adsorption is a commonly used method for the treatment of dye wastewater. It can selectively adsorb dye molecules, and the effect is evident. Developing an efficient adsorbent and studying its adsorption mechanism are important research directions. Currently, a portion of perlite tailing is neglected because of limitations in perlite processing [7]. Such neglect results in resource wastage and environmental pollution [8]. To expand its application, perlite tailing is processed into expanded perlite (EP), which is an abundant and economical material [9], and used as an adsorbent. This action can facilitate EP change from single building materials to green environmental materials. With these 
considerations, EP were selected as a adsorbent and its adsorption performance for MB was examined in this study.

\section{EXPERIMENTAL}

\section{Materials}

Commercially available EP (0.25-0.5mm) was chosen as a raw material. Screening EP to remove the fine sand from EP, and then the sample was washed 3-5 times with distilled water, followed by drying at $120^{\circ} \mathrm{C}$ until constant weight.

\section{Methods}

All batch experiments were performed at desired dosage, contact time, temperature, and $\mathrm{pH}$ value using the necessary EP in 250mL conical flasks containing $50.00 \mathrm{~mL}$ of $\mathrm{MB}$ solution (20 mg/L, pH 5.67) under $140 \mathrm{rpm}$. The effect of dosage on the adsorption capacity of EP and removal rate of MB were performed with $0.1,0.2,0.3,0.5,0.8$ and $1.0 \mathrm{~g}$ EP for $80 \mathrm{~min}$ at $20^{\circ} \mathrm{C}$. The samples was collected at $20,40,60,80,100$ and 120 min to investigate the effect of shaking time on the adsorption. The temperature was adjusted to $20,30,40,50,60,70$ and $80^{\circ} \mathrm{C}$ to determine the effect of temperature. During the determination of the effect of $\mathrm{pH}$ on the adsorption capacity of the absorbents and $\mathrm{MB}$ removal rate, the $\mathrm{pH}$ of $\mathrm{MB}$ solution was adjusted to 3, 5, 7, 9 and 10 with $0.10 \mathrm{~mol} / \mathrm{L}$ of $\mathrm{NaOH}$ or $\mathrm{HCl}$ solution by using a $\mathrm{pH}$ solution meter.

For the adsorption isotherm study, batch experiments were conducted by oscillating $50.00 \mathrm{~mL}$ of various concentrations of $\mathrm{MB}$ solutions ( $\mathrm{pH}$ 5.67) with $\mathrm{EP}$, the dosage of which was the best, until adsorption equilibrium was reached at $20^{\circ} \mathrm{C}$. For the kinetic study, $20 \mathrm{mg} / \mathrm{L}$ of $\mathrm{MB}$ solutions $(50.00$ $\mathrm{mL}, \mathrm{pH}$ 5.67) were oscillated with the adsorbent, the dosage of which was the best, at $20^{\circ} \mathrm{C}$ for a predetermined time. Additionally, the pore structure of EP was examined by field emission scanning electron microscope (FESEM).

The removal rate and adsorption capacity of EP were calculated with Equations (1) and (2) [8], respectively.

$\mathrm{R}_{\mathrm{e}}=\frac{\left(C_{0}-C_{e}\right)}{C_{0}} \times 100 \%$

where $\mathrm{Re}(\%)$ is the removal rate of $\mathrm{MB}, \mathrm{C} 0(\mathrm{mg} / \mathrm{L})$ is the initial concentration of $\mathrm{MB}$, and $\mathrm{Ce}(\mathrm{mg} / \mathrm{L})$ is the equilibrium concentration of $\mathrm{MB}$ in the solution.

$\mathrm{q}_{\mathrm{e}}=\frac{\left(C_{0}-C_{e}\right) V}{M}$

where qe $(\mathrm{mg} / \mathrm{L})$ is the amount of MB adsorbed on the adsorbent, $\mathrm{C} 0(\mathrm{mg} / \mathrm{L})$ is the initial concentration of $\mathrm{MB}, \mathrm{Ce}(\mathrm{mg} / \mathrm{L})$ is the equilibrium concentration of $\mathrm{MB}$ in the solution, $\mathrm{V}(\mathrm{L})$ is the volume of the solution used, and $\mathrm{M}(\mathrm{g})$ is the mass of the adsorbents used.

\section{RESULTS AND DISCUSSION}

\section{Effect Of Dosage On Adsorption}

Figure 1 shows that with the increase in the dosage of EP, the removal rate of MB gradually increased. However, the increment rate gradually decreased. When the dosage of EP reached a certain 
level, the removal rate of MB stabilized probably because a small amount of EP could not provide sufficient adsorption sites. When the amount of EP was sufficient, MB was basically removed; the removal rate did not change and was stable. With the increase in EP dosage, the adsorption capacity of the three adsorbents decreased. The increase in EP dosage possibly increased the adsorption sites and reduced the amount of $\mathrm{MB}$ adsorbed per unit area. As a result, the MB adsorption amount per unit mass of the adsorbent declined. When the dosages of EP was 0.8, the highest MB removal rate was achieved at $93.74 \%$. Therefore, the ideal dosages of EP was $0.8 \mathrm{~g}$. A good removal effect can be obtained at EP, and the amount of EP can be reduced.

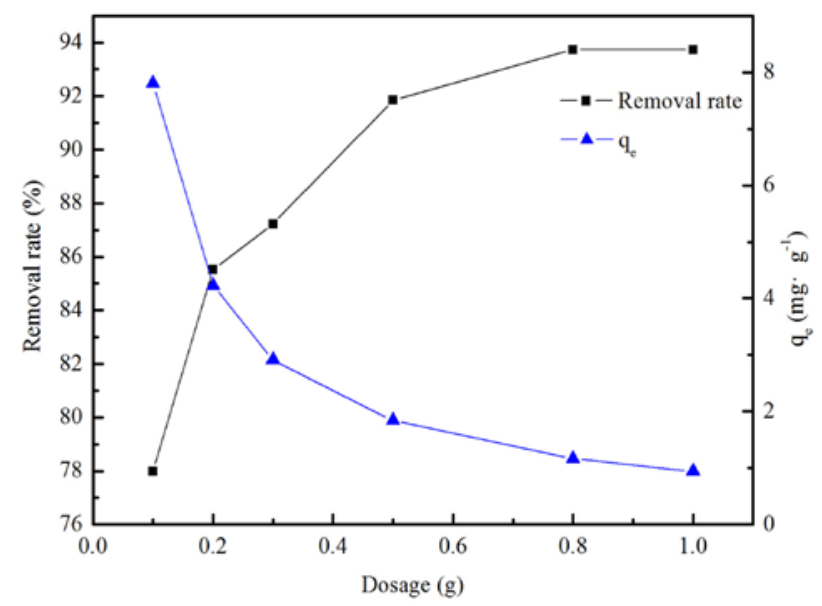

FIGURE 1. Effect of dosage of EP on the removal of MB

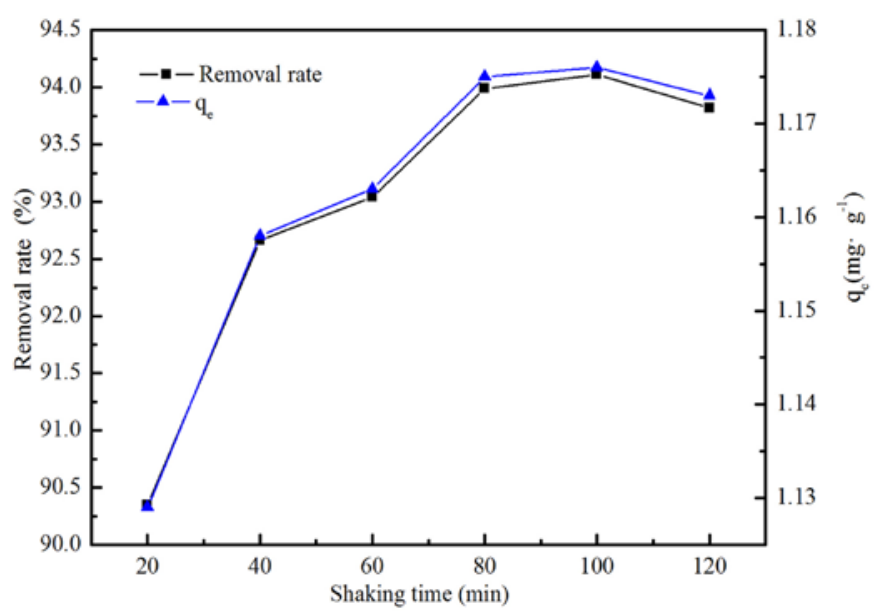

FIGURE 2. Effect of shaking time on the removal of MB

\section{Effect Of Shaking Time On Adsorption}

The effect of time on MB adsorption is shown in Figure 2. When the dosage of EP and other adsorption conditions were unchanged, the removal rate of MB and adsorption capacity increased with the increase in time and eventually stabilized. In the beginning of the adsorption reaction, the removal rate of MB was high for two main reasons. First, the concentration of MB in the solution was high, so the adsorption impetus was large [10]. Second, many unoccupied high-energy adsorption sites existed on the surface of adsorbents [11], such that the possibility of MB coming into contact with EP increased. Consequently, the adsorption reaction was implemented quickly. Afterward, with MB being constantly adsorbed, the concentration of the MB solution and adsorption impetus declined. With the 
increase in MB on the adsorbents' surface, the available adsorption sites gradually decreased. Figure 2 shows that when the contact time was $100 \mathrm{~min}$, the removal rate of MB and the adsorption capacity of expanded perlite reached the maximum, which were $94.12 \%$ and $1.18 \mathrm{mg} / \mathrm{g}$, respectively. Thus, 100 min were selected as ideal adsorption time for EP.

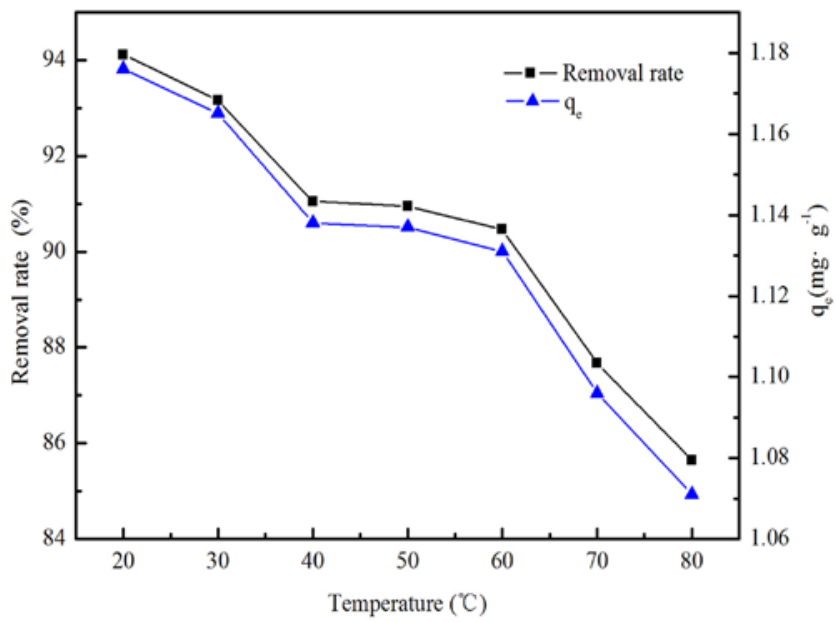

FIGURE 3. Effect of temperature on the removal of MB

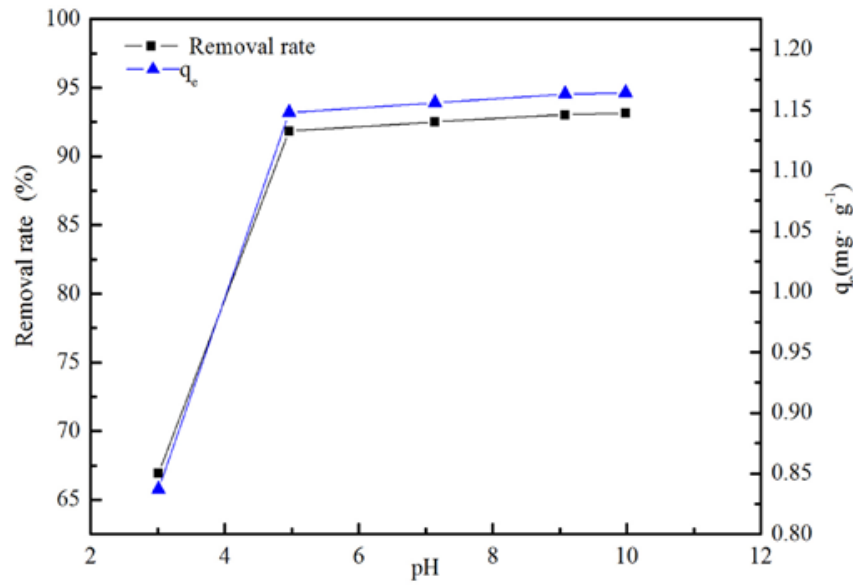

FIGURE 4. Effect of $\mathrm{pH}$ on the removal of $\mathrm{MB}$

\section{Effect Of Temperature On Adsorption}

The effect of temperature on absorption is presented in Figure 3. The Figure 3 indicates that the removal rate of $\mathrm{MB}$ and the adsorption capacity of EP gradually decreased with the increase in temperature, suggesting that the adsorption process was an exothermic reaction $[6,12,13]$. Thus, the increase in temperature decreased adsorption efficiency. Additionally, with the increase in temperature, the average kinetic energy of the MB molecules increased. The increase in the kinetic energy of adsorbed MB molecules provided them adequate energy to overcome the attraction force between MB and the adsorbent and to desorb to the aqueous solution [13]. That is, the increase in temperature was beneficial to desorption rather than adsorption. When the temperature was high, MB was difficult to adsorb on the surface of EP. Therefore, a low temperature is more favorable for MB removal than a high one. At a temperature of $20^{\circ} \mathrm{C}$, the removal rate of $\mathrm{MB}$ and the adsorption capacity of EP reached the maximum, which was $94.12 \%$ and $1.18 \mathrm{mg} / \mathrm{g}$, respectively. Therefore, $20^{\circ} \mathrm{C}$ was selected as the optimal temperature in the subsequent experiments. 


\section{Effect Of PH On Adsorption}

The effect of $\mathrm{pH}$ on absorption is shown in Figure 4. For EP, MB removal rate and the adsorption capacity of EP significantly increased as the $\mathrm{pH}$ of the solution increased. EP had a low adsorption rate at a low $\mathrm{pH}(\mathrm{pH}<5)$. As $\mathrm{pH}$ decreased, $\mathrm{H}^{+}$on the surface of EP increased, and negative electricity decreased. Competitive adsorption and electrostatic repulsion occurred between $\mathrm{H}^{+}$and the cation of MB. Therefore, $\mathrm{MB}$ removal was low. At a high $\mathrm{pH}(\mathrm{pH}>5), \mathrm{OH}^{-}$on the surface of expanded perlite increased, such that the negative electricity of EP also increased [14, 15]. Therefore, with the increase in the $\mathrm{pH}$ of the solution, the removal rate of MB and the adsorption capacity of EP increased.

\section{Adsorption Isotherm}

The adsorption isotherm is important in the design of adsorption systems. Two isotherm equations, Langmuir and Freundlich, were investigated in this study [16]. The Langmuir isotherm is suitable for monomolecular layer adsorption [17]. The Langmuir and Freundlich equations are represented as Eqs. (3) and (4), respectively.

$$
\frac{C_{e}}{q_{e}}=\frac{1}{q_{m} K_{L}}+\frac{C_{e}}{q_{m}}
$$

where qe (mg/g) is equilibrium MB dye adsorption quantity on the adsorbent, qm $(\mathrm{mg} / \mathrm{g})$ is the monolayer capacity of the adsorbent, $\mathrm{KL}(\mathrm{L} / \mathrm{mg})$ is the adsorption constant, and $\mathrm{Ce}(\mathrm{mg} / \mathrm{L})$ is the equilibrium concentration of MB in the solution [13]. According to Eq. (3), the plot of Ce/qe versus Ce should be a straight line with a slope of $1 / \mathrm{qm}$ and intercept of $1 /(\mathrm{qm} \mathrm{KL})$, when adsorption follows the Langmuir equation.

$$
\ln q_{e}=\ln K_{F}+\frac{1}{n} \ln C_{e}
$$

where KF and $\mathrm{n}$ are Freundlich adsorption isotherm constants that indicate the extent of the adsorption and the degree of nonlinearity between solution concentration and adsorption, respectively. qe (mg/g) is equilibrium dye concentration on the adsorbent, and $\mathrm{Ce}(\mathrm{mg} / \mathrm{L})$ is equilibrium dye concentration in the solution.

The adsorption isotherm data of EP are shown in Table 1. The R2 of the Langmuir adsorption isotherm was 0.9802. A significant difference was observed between fitting qm with $4.83 \mathrm{mg} / \mathrm{g}$ and experimental qm with $3.89 \mathrm{mg} / \mathrm{g}$. The R2 of the Freundlich adsorption isotherm was 0.9782 . Thus, adsorption process of EP was incompatible with neither the Langmuir model nor the Freundlich model.

\section{Adsorption Kinetics}

In this paper, pseudo first-order and pseudo second-order kinetic models [2, 11, 16, 18] were used to investigate the adsorption process of MB. The pseudo first-order and pseudo second-order kinetic model equations both assume that adsorption amount is related only to adsorption time. The parameters of the two model equations were estimated with the experimental data. The two model equations are expressed as Eqs. (5) and (6), respectively.

$$
\begin{array}{llllllll}
\ln \left(\mathrm{q}_{\mathrm{e}}\right. & - & \left.\mathrm{q}_{\mathrm{t}}\right) & = & \ln \mathrm{q}_{\mathrm{t}} & - & \mathrm{K}_{1} \mathrm{t}
\end{array}
$$


where qe (mg/g) is equilibrium MB adsorption quantity on the adsorbent, qt $(\mathrm{mg} / \mathrm{g})$ is adsorption quantity at a particular time, $\mathrm{K} 1$ (min-1) is the adsorption constant, and $\mathrm{t}$ (min) is the adsorption reaction time.

$$
\frac{t}{q_{t}}=\frac{1}{K_{2} q_{e}{ }^{2}}+\left(\frac{1}{q_{e}}\right) t
$$

where K2 is the adsorption constant of the pseudo second-order kinetics model equation ( $\mathrm{g} / \mathrm{mg} \bullet \mathrm{min}$ ).

The adsorption kinetics data of the three adsorbents are shown in Table 2. The R2 of the pseudo second-order kinetic model equation was 0.9999, and the qe experimental value of $1.18 \mathrm{mg} / \mathrm{g}$ and the calculated value of $1.19 \mathrm{mg} / \mathrm{g}$ were close. Compared with the pseudo first-order kinetic model, the pseudo second-order kinetic model could better describe the process of MB absorption onto the surface of EP.

TABLE 1. Fitting Results of Langmuir Equation and Freundlich Equation

\begin{tabular}{|c|c|c|c|c|c|c|}
\hline & \multicolumn{3}{|c|}{ Langmuir Equation } & \multicolumn{3}{|c|}{ Freundlich Equation } \\
\hline \multirow{3}{*}{$\begin{array}{l}\text { Expanded } \\
\text { Perlite }\end{array}$} & & $723 x+$ & & & $096 x^{+}$ & \\
\hline & $\mathrm{q}_{\mathrm{m}}$ & $\mathrm{K}_{\mathrm{L}}$ & $\mathrm{R}^{2}$ & $\mathrm{~K}_{\mathrm{F}}$ & $\mathrm{n}$ & $\mathrm{R}^{2}$ \\
\hline & $4.83 \mathrm{mg} / \mathrm{g}$ & 0.08 & 0.9802 & 1.08 & 3.23 & 0.9782 \\
\hline
\end{tabular}

TABLE 2. Fitting results adsorption kinetics of MB onto EP

\begin{tabular}{|c|c|c|c|c|c|}
\hline & Kinetic parmeter & kinetics equation & $\mathbf{R}^{2}$ & $\begin{array}{l}\text { experiment } \\
\text { value of } q_{e}\end{array}$ & $\begin{array}{c}\text { calculated value } \\
\text { of } \mathbf{q}_{\mathrm{e}}\end{array}$ \\
\hline Expanded & pseudo-first-order & $y=-0.03072 x-2.83541$ & 0.6343 & $1.18 \mathrm{mg} / \mathrm{g}$ & $0.06 \mathrm{mg} / \mathrm{g}$ \\
\hline Perlite & $\begin{array}{l}\text { pseudo-second-or } \\
\text { der }\end{array}$ & $y=0.84422 x+0.77926$ & 0.9999 & $1.18 \mathrm{mg} / \mathrm{g}$ & $1.19 \mathrm{mg} / \mathrm{g}$ \\
\hline
\end{tabular}

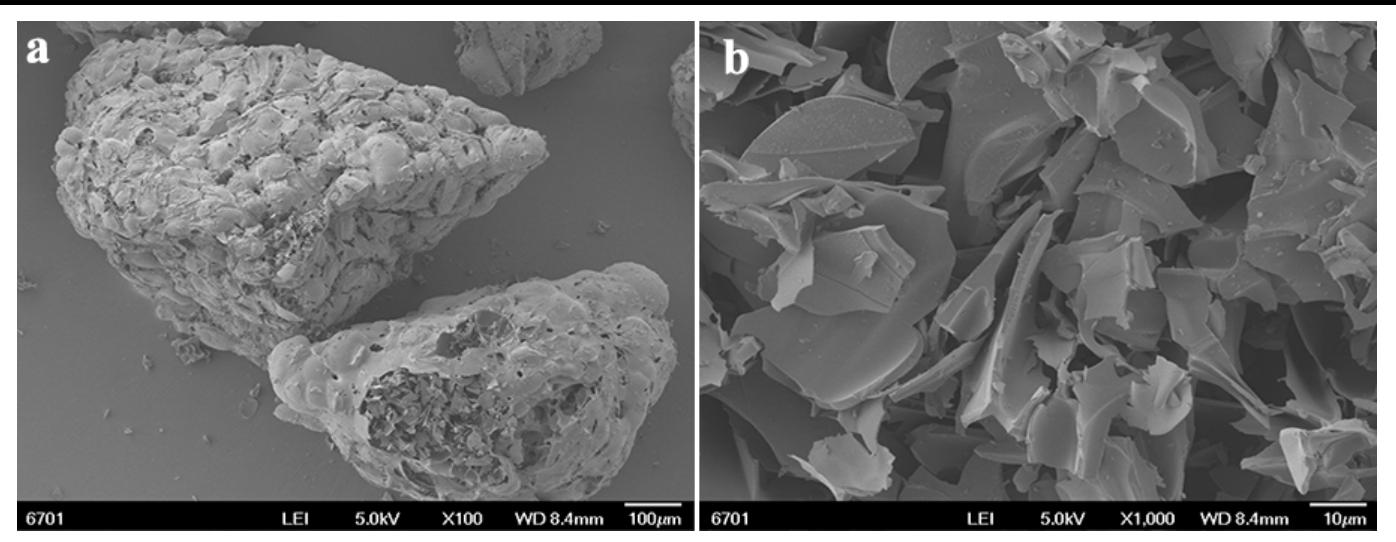

FIGURE 5. FESEM images of EP at different magnifications (a: x100; b: x1000)

\section{Characterization Of Three Adsorbents}

The adsorbing materials of EP were investigated further by FESEM. The FESEM images are shown in Figure 5. The surface of EP is loose and porous (Figure 5a). And the internal of EP presented a loose 
fragments structure(Figure 5b). The arrangement of fragments is irregular. The size of pores and the gap between fragments were about 2-10 um. The structure of EP was macropore ( $>50 \mathrm{~nm}$ ) [19], which played a positive role in removing $\mathrm{MB}$ from aqueous solution that allowing $\mathrm{MB}$ molecules to quickly enter internal holes [20]. Thus, EP showed a good absorption properties, consistent with the experimental results.

\section{CONCLUSION}

Experiment data on MB absorption by EP showed that the optimal dosage of EP, adsorption time, temperature and $\mathrm{pH}$ was $0.80 \mathrm{~g}, 100 \mathrm{~min}, 20^{\circ} \mathrm{C}$ and 5.67, respectively. Under ideal experimental parameters, the MB removal efficiency was $94.12 \%$. The adsorption process was inconsistent with the Langmuir and Freundlich models. The fitting result of the kinetic model equation suggested that the pseudo second-order kinetic model can describe this process well. The experimental results indicated that $\mathrm{EP}$ is a potential adsorbent for the treatment of MB wastewater.

\section{ACKNOWLEDGEMENTS}

This study was supported by the National Natural Science Foundation of China (21667017), the Provincial Natural Science Foundation of Gansu (1506RJZA102), the College Students Training Project for Creative and Entrepreneurship of China (201510731005).

\section{REFERENCES}

1. P. Sharma, H. Kaur, M. Sharma, V. Sahore, A review on applicability of naturally available adsorbents for the removal of hazardous dyes from aqueous waste, Environ. Monit. Assess. 183 (2011) 151-195

2. P. Kumar, S. Ramalingam, K. Sathishkumar, J. Korean, Removal of methylene blue dye from aqueous solution by activated carbon prepared from cashew nut shell as a new low-cost adsorbent, Korean J. Chem. Eng. 28 (2011) 149-155.

3. D. Suteu, C. Zaharia, A. Muresan, R. Muresan, A. Popescu, Using of industrial waste materials for textile wastewater treatment, Environ. Eng. Manag. J. 8(2009) 1097-1102.

4. S. Thakur, S. Pandey, O. A. Arotiba, Development of a sodium alginate-based organic/inorganic superabsorbent composite hydrogel for adsorption of methylene blue. Carbohydr. Polym. 153 (2016) 34-46.

5. A. F. Alkaim, Z. Sadik, D. K. Mahdi, S. Alshrefi, A. Al-Sammarraie, F. Alamgir, P.Singh, A. Aljeboree, Preparation, structure and adsorption properties of synthesized multiwall carbon nanotubes for highly effective removal of maxilon blue dye, Korean J. Chem. Eng. 32 (2015), 2456-2462.

6. G. Liu, Z. Hu, R. Guan, Y. Zhao, H. Zhang, B. Zhang, Efficient removal of methylene blue in aqueous solution by freeze-dried calcium alginate beads, Korean J. Chem. Eng. 33 (2016), 3141-3148.

7. D. Kramar, and V. Bindiganavile, Mechanical properties and size effects in lightweight mortars containing expanded perlite aggregate, Mater. Struct. 44 (2011) 735-748.

8. G. Ghanizadeh, G. Asgari, Adsorption kinetics and isotherm of methylene blue and its removal from aqueous solution using bone charcoal, Reac. Kinet. Mech. Cat. 102 (2011), 127-142.

9. J. Liu, X. S. Zhu, Ionic Liquid-Immobilized Expanded Perlite Solid-Phase Extraction for Separation/Analysis of Bisphenol A in Food Packaging Material, Food Anal. Methods, 9 (2016), 
605-613.

10. W. Zhu, H. Song, C. Jia, S. Yao, Fabrication and adsorption property of novel adsorbent for potential application to wastewater with Fe(III) ions, J. Cent. South. Univ. 21 (2014) 2832-2836 .

11. D. Zhang, Y. Ma, H. Feng, H., Luo, J. Chen, Y. Hao, Removal of methylene blue from aqueous solution by a carbon-microsilica composite adsorbent, Korean J. Chem. Eng. 29 (2012), 775-780.

12. R. Akkaya, Effects of $\mathrm{pH}$, concentration and temperature on radionuclides sorption onto polyhydroxyethyl methacrylate-expanded perlite composite, J. Radioanal Nucl. Chem. 295 (2013), 351-355

13. A. W. Marczewski, M. Seczkowska, A. Deryło-Marczewska, M. Blachnio, Adsorption equilibrium and kinetics of selected phenoxyacid pesticides on activated carbon: effect of temperature. Adsorption. 22 (2016) , 777-790.

14. M. An, M. Alkan, Y. Ongane, Adsorption of methylene blue from aqueous solution onto perlite. Water Air Soil Pollut. 120 (2000)229-248.

15. H. Ghassabzadeh, M. Torab-Mostaedi, A. Mohaddespour, M. G.Maragheh, S. J. Ahmadi, P. Zaheri, Characterizations of $\mathrm{Co}(\mathrm{II})$ and $\mathrm{Pb}$ (II) removal process from aqueous solutions using expanded perlite, Desalination, 261 (2010), 73-79.

16. M. Stoia, C. Păcurariu, R. Istratie, D. Nižňanský, Solvothermal synthesis of magnetic FexOy/C nanocomposites used as adsorbents for the removal of methylene blue from wastewater, J. Therm. Anal. Calorim. 121 (2015), 989-1001.

17. H. Aysan, S. Edebali, C. Ozdemir, M. Celik Karakaya, N. Karakaya, Use of chabazite, a naturally abundant zeolite, for the investigation of the adsorption kinetics and mechanism of methylene blue dye, Microporous Mesoporous Mater. 235 (2016) 78-86.

18. S. Gao, L. Liu, Y. Tang, D. Jia, Z. Zhao, Y. Wang, Coal based magnetic activated carbon as a high performance adsorbent for methylene blue. J. Porous. Mater., 23 (2016) 877-884.

19. Z. Yue, J. Economy, Nanoparticle and Nanoporous Carbon Adsorbents for Removal of Trace Organic Contaminants from Water, J. Nanopart. Res. 7 (2005), 477-487.

20. X. Bu, L. Wang, Y. Huang, Effect of pore size on the performance of composite adsorbent. Adsorption, 19 (2013), 929-935. 